\title{
Menuju Ecocentrisme: Menapaki Jalan Ekologis yang Etis
}

\author{
Ghanesya Hari Murti \\ Politeknik Negeri Jember \\ ghanesyaharimurti@yahoo.co.id
}

\begin{abstract}
Abstrak
Upaya untuk menghidupkan relasi yang harmonis antara manusia dengan alam selalu gagal dan menemukan polemik kendati kondisi tersebut selalu diidealkan bersama. Tentunya, usaha tersebut tidak hanya membutuhkan pikiran kritis tapi juga dorongan etis yang kuat. Posisi etis itu ada pada upaya untuk pindah dari cara berpikir antroposentris yang berpihak untuk mendominasi alam demi kebutuhan manusia menuju cara berpikir ekosentris yang menganggap bahwa kepentingan alam juga harus diikutkan haknya sebagai subjek hukum. Tulisan ini dengan begitu hendak 1) memberikan ilustrasi posisi etis pada dua peristiwa yang melibatkan alam sebagai sebagai subjek dan non subjek hukum, 2) mengurai argumentasi etis yang betengkar dan saling melegitimasi tindakan moral pada alam 3) menunjukkan argumentasi para intelektual khas libertarian Amerika yang berupaya menunjukkan posisi ecocentris yang mereka alami. Sederet perjalanan pemikiran para environmentalists itu dimaksudkan untuk merunut argumentasi akademis mengapa memberikan legal standing bagi sungai ataupun sebuah taman nasional menjadi normal. Sehingga muncul konsekuensi bahwa alam juga mampu menuntut hak yang sama di mata hukum untuk dihitung kepentingannya yang dilukai oleh manusia. Hanya dengan begitu, hak sungai untuk tetap jernih, burung untuk tetap berkepak dan lembah untuk tetap berlekuk bisa dinikmati sebagai buah perkembangan peradaban yang lebih etis.
\end{abstract}

Kata Kunci: ekosentrisme; ekologi; etis; subjek; alam

\begin{abstract}
The struggle to bridge harmonious relations between humans and nature always fail and find polemics even though these ideal condition is always promoted. Indeed, this effort requires not only critical thinking but also a strong ethical drive. The ethical position is to drive the anthropocentric thinking which is in favor of dominating nature for human needs to ecocentric thinking which considers the interests of nature must also be included as legal subjects. This article thus proposes to 1) provide an illustration of the ethical position on two cases involving nature as a subject and non-legal subject, 2) break down conflicting ethical arguments which legitimize such moral actions to be applied on nature 3) show the arguments of libertarian American intellectuals in conjunction with the ecocentric position they exercised. The history of selected environmentalists are intended to show the current academic argument on why giving the legal standing for the river or a national park becomes academically corect. The argument implies that nature is
\end{abstract}


also able to demand the same rights before the law if crime is done by humans. This argument strongly encourages that the river has right to remain clear, the birds to keep flapping and the curve of the valley to stay steep as the signs of a more ethical civilization.

Keywords: ecocentrism; ecology; ethic; subject; nature

\section{PENDAHULUAN}

Dapat dipastikan gairah untuk hidup harmonis dengan alam adalah imajinasi yang selalu didambakan bersama. Namun faktanya usaha tersebut mengalami kontradiksi pada pengalaman keseharian. Peradaban selalu menagih adanya semacam perubahan pandangan sehingga tidak terjadi ketimpangan dalam mempersepsi alam hanya sebagai objek yang harus ditaklukkan. Usaha peradaban untuk tumbuh, disambut oleh pengetahun melalui hukum pada tahun 2014, Te Urewara, sebuah taman nasional dengan luas 821 mil persegi, dilepaskan status kepemilikan formalnya oleh pemerintah New Zealand dan kemudian diberikan status sebagai personhood (New York Times, 2016), atau secara radikal bisa disebut sebagai citizen yang dilindungi haknya agar setiap pohon dijamin kepentingan untuk tumbuh dan sungai memiliki hak untuk mengalirkan air yang jernih. Di lain sisi, di Indonesia ada pameran kejahatan alam dimana setahun setelahnya, tepatnya tanggal 2015, terjadi pembakaran besar-besaran yang diduga melibatkan 56 perusahan dan berakibat 16 perusahaan dibekukan dan hanya tiga yang dicabut izinnya. Pada peristiwa tersebut, alam tidak ditempatkan sebagai korban korporasi karena secara implisit menkopolhukam melihat korban hanya dikenali apabila dia adlah manusia. Secara verbatim terlihat pada ucapan "Kita akan membuat seminimal mungkin asap. Belajar dari pengalaman tahun ini. Tentu kita tidak mau lagi rakyat kita tercemar dengan asap lebih banyak ke depan," (BBC, 2018). Pernyataan itu tidak hanya menunjukkan bahwa tidak adanya keseriusan dalam menanggulangi kejahatan korporasi pada alam namun juga memastikan bahwa korban dari peristiwa tersebut adalah manusia dan bukan alam. Tindakan tersebut tentunya menghina lingkungan karena secara implisit menyatakan bahwa subjek hukum hanya manusia. Dua peristiwa tersebut dapat menunjukkan contrasting ideas dan juga jarak peradaban tentang bagaimana pohon harus ditempatkan dalam dua peristiwa tersebut. Ide tentang memberikan hak pada pohon adalh gagasan baru yang mungkin akan diterima secara sumir pada pandangan yang melihat hanya kepentingan manusia yang harus dihitung jika terjadi peristiwa pembakaran hutan.

Tulisan ini berdasarkan dua peristiwa diatas ingin menunjukkan adanya dua jenis supply etis berbeda yang tengah berduel untuk memberikan legitimasi moral pada alam. Pertengkaran itu kemudian dapat disebut sebagai pertengkaran pandangan antara antroposentris dan eccocentris, dimana yang pertama beranggapan bahwa pusat ada pada manusia dan bukan alam sehingga alam adalah objek utiliter, sedangkan yang kedua memberikan tekanan bahwa pusat menjadi lenyap dan harus menemukan titik equilibrium atau keseimbangan sehinga semua yang hidup 
dan tak hidup harus juga dihitung memiliki hak yang sama, bahkan dipastikan untuk dilingdungi secara hukum.

\section{PEMBAHASAN}

Subjek penelitian ini adalah 5 orang penutur Bahasa Indonesia dengan aksen Jawa (secara khusus Jawa Timuran). Kelima orang tersebut memiliki rentang usia antara 20 sampai 22 tahun dan berasal dari beberapa kota di Jawa Timur, antara lain Malang (2 orang), Surabaya (2 orang) dan Tulungagung (1 orang). Untuk menghindari terjadinya bias jender, kelima orang tersebut terdiri dari 3 pria dan 2 wanita. Selanjutnya, para subjek disodori sebuah cerita pendek yang memuat kata-kata dengan konsonan hambat. Lalu para subjek melafalkan cerita tersebut dan suara mereka direkam menggunakan perekam suara.

Pendekatan kualitatif digunakan dalam penelitian ini, dimana data yang didapatkan dianalisis untuk mengetahui transfer fonologis apa saja yang ditemukan saat penutur Bahasa Indonesia yang memiliki aksen Jawa mengucapkan kata-kata yang mengandung konsonan hambat di dalam Bahasa Indonesia. Selain itu, hasil analisis diserahkan kepada seorang ahli fonologis untuk divalidasi.

\section{Duel Etis: Ecocentris versus Antroposentris}

Ecocentrisme dan antroposentisme dikenal sebagai pertengkaran ekologis yang memberikan legitimasi moral untuk memperlakukan alam dengan cara tertentu. Antrposentris ingin memberikan argumen bahwa alam menjadi mempesona selama dia memliki fungsi atau keguanaan bagi manusia (Garrard, 2004:68) khas utiltiterianisme. Sedangkan pandangan ecocentris ingin membatalkan pandangan itu karena kepentingan manusia tidak menjadi satusatunya hal yang harus dihitung dalam merumuskan nilai yang diluar dirinya, tapi juga keperntingan binatang, tumbuhan bahkan ekosistem sehingga alam tidak lagi ditatap hanya pada fungsinya secara utiliter bagi manusia (Mackinnon dan Fiala, 2015: 404).

Dua polarisasi pikiran tersebut bertengkar namun juga memberikan supply ide mengapa pembakaran hutan dinggap bukan kejahatan serius karena korban yang dimaksud adalah manusia yang tengah disiksa paru-parunya oleh asap. Antroposentrisme dengan begitu memberikan legitimasi bahwa pohon tidak memiliki hak untuk menagih keadilan karena ecological justice dihambat untuk diucapkan ketika hanya manusia yang bisa disebut sebagai korban. Berlawanan dengan itu, pandangan ecocentris justru ingin memulihkan relasi yang timpang tersebut dengan memberikan bahwa tumbuhan terutama pohon yang terbakar seharusnya punya hak untuk bertumbuh dan berbuah.

Relasi yang dibangun oleh cara berpikir ecocentris ingin merekonstruksi ulang relasi yang dihapus oleh narasi modern yang pro pada antroposentrisme dengan cara mencicil pada semanagat kultural yang masih menyisakan semangat ecocultural persis seperti yang terjadi di New Zealand ketika melibatkan pandangan suku Maori untuk meluluskan produk hukumnya (The Guardian, 2017). Sehingga seolah-olah pengalaman kelekatan antara manusia dan alam yang harmonis lenyap secara kultural dan digantikan transaksi secara utiliter-ekonomis, dan fakta masalah ekologis semakin memburuk. Pohon kelapa sawit hanya 
dianggap menguntungkan manusia ketika dia produktif sehingga ketika dia tidak lagi produktif dan biaya untuk memangkas pohon tersebut cukup besar maka pembakaran menjadi hal rasional, karena fungsi utiliter dari pohon sawit telah hilang. Pikiran ini diedarkan dan melegitamasi perlakuan manusia untuk mendominasi alam, sekaligus didorong oleh hasrat ekonomi yang kuat dan memunculkan hirarkisasi manusia dan alam yang makin tajam. Dominasi pikiran antroposentris juga pasti memandang aneh apa yang terjadi di New Zealand ketika pemerintah memberikan status legal standing sebagai personhood karena dianggap tidak lazim. Alam semakin terdesak dan tidak memiliki hak untuk melawan, kendati secara realitas manusia bisa merasakan bahwa alam mampu merespon dominasi tersebut. Ecocentris memberi peluang bagi alam untuk menulis hukumnya sendiri. Hukum itu muncul pada tanah longsor ketika banyak pohon ditebang ataupun tumbuhnya penyakit ketika limbah pabrik dibuang ke aliran air. Tentunya pikiran ecocentris berupaya menarasikan sikap etis bahwa alam juga punya hak, dan hal tersebut hanya dimungkinkan jika kondisi warga dalam suatu masyarakat tahu betul tentang konsep hak. Hak yang selama ini dianggap natural rights yang berada pada manusia harus berpindah dan dikenal sebagai rights of nature.

\section{Hak Alam: dari Rachel Carosn, Murray Bookchin, hingga Christopher D Stone}

Perspektif hak yang selalu didukung oleh semangat libertarian khas masyarakat Amerika ternyata melahirkan pemikiran hak bagi alam pada masa - masa awal. Libertarian mampu memaksimalkan konsep hak karena ingin berpindah dari perspektif utiliter khas Bentham untuk kemudian berpindah pada ide libertarian Kant. Bagi libertarian, hak untuk mendapat kebahagian ketika memproduksi justice tidak bisa diseragamkan bahkan dikuantifisir seperti yang digambarkan oleh paham utiliter karena jenis hak untuk memperoleh kebahagian adalah hal yang unik dan berbeda "the counter-utilitarian idea that there is a difference between preferences and values and that considerations of individual rights tempers calculations of aggregate utility" (Millennium Ecosystem Assessment, 2013). Ide kontrsnya dapat diurai sebagai dua kutub oposisi biner, dimana pikiran utiliter mendukung antroposentrisme dengan memberikan argumen bahwa keadilan hanya dimungkinkan jika produksi kebahagian didapatkan secara maksimal bagi manusia sedangkan perkembangan pikiran libertarian memberikan versi keadilan dengan tujuan bahwa kebahagian adalah sesuatu yang spesifik, particular dan unik sehingga kebahagiaan sehingga perlu dirumuskan berulang-ulang. Seseorang yang biasa makan tempe tahu tidak dapat dianggap bahagia hanya karena ada orang yang menikmati daging tiap harinya.

Libertarianism tumbuh subur dalam intelektual America karena pengalaman sejarah masyarakatnya pernah mengalami siksaan aristokrasi dan kelas yang membuat akses hak menjadi buruk pada zaman itu. Pikiran libertarian berkembang untuk kemudian tidak hanya menguji jenis kebahagian dan keadilan pada manusia tapi juga alam yang sangat mungkin masih asing untuk dipahami. 
Rachel Carson kemudian membuka pembicaraan tersebut dalam bukunya "The Silent Spring" (1962) yang melihat ada hak alam yang terancam ketika penggunaan pestisida, atau DDT menjadi signifikan bdan massif penggunaanya demi perkembangan industri agrikultur. Pestisida yang dimaksudkan menjadi alat kontrol hama di ladang nyatanya justru memunculkan bahaya yang lebih besar bagi jejaring ekologis. Bahaya tersebut diabaikan oleh bisnis agrikultur yang subur paska perang dunia II hingga mentolerir penyebaran cairan kimia dengan pesawat terbang tanpa ijin. Secara politis penggunaan kata insecticides digunakan untuk mengkaburkan sifat kimia dari pestisida walaupun nyatanya kata yang pas untuk diucapkan adalah biocides (Carson, 1994:13). Kendati hama mampu ditanggulangi dengan cara menyediakan predator yang disediakan oleh alam nyatanya jalan tersebut tidak ditempuh karena pestisida dianggap lebih efektif dan ekonomis. Carson menjelaskan logika alam pada public Amerika yang ketika itu buta huruf pada narasi ekologi yang dia sebut sebagai web of life. Argumen Carson menunjukkan jalan alternatif bagi manusia untuk bisa hidup berdampingan dengan alam melalui semangat metafor puisi Robert Frost yang sangat terkenal The Road Not Taken. "the other fork of the road-the one 'less traveled by'-offers our last, our only chance to reach a destination that assures the preservation of our earth" (Carson, 1994:144). Jalan ekologis untuk membasmi hama dengan menunjukkan rantai makanan yang pas pada hama dianggap jalan yang using, hanya karena manusia tidak paham rantai ekosistem yang ditulis oleh alam sebagai web of life "the earth's vegetation is part of a web of life in which there are intimate and essential relations between plants and the earth, between plants and other plants, between plants and ani mals" (Carson, 1994:41). Carson yang seorang biologis tahu betul jalan tersebut sepi dan sulit ditapaki tapi hanya itu jalan yang menyelamatkan ekologi.

Jalan pikiran tersebut kemudian dilebarkan oleh Murray Bookchin yang mulai mengenali adanya hak bagi alam untuk dibebaskan dari kendali antropsentrisme. The Ecological Freedom (1982) menjadi penanda perpindahan bahwa hak untuk bebas tidak lagi melekat pada manusia tapi juga alam. Bookchin menawarkan konsep social ecologi yang meletakkan fondasi pemahaman bahwa isu tentang alam juga berkaitan dengan isu sosial. Social ecology berangkat dari semangat Marxian untuk menunjukkan relasi kontestatif alam dan manusia dimana hirarki yang terjadi adalah bentuk dominasi manusia pada alam. Relasi mutual harusnya bisa dipraktikan dan bukan relasi kontestatif yang menumbuhkan konflik "the conflict in nature between different kinds of organisms has been popularly expressed in phrases like "struggle for existence" and "survival of the fittest." (Bookchin, 1982:384). Konsep itu menjaring seluruh sistem berpikir Bookchin untuk melihat kemungkinan mengurai hirarkisasi dan praktik dominasi melalui fasilitas politik. Konstruksi politik di Amerika menyediakan ruang bagi demokrasi dan libertarianism untuk melahirkan libertarian municipalism atau desentralisasi yang memungkinkan komunitas untuk mengupayakan kepentingannya sendiri dan alam. Prinsip libertarian dianggap penting karena menekankan jenis hak yang melekat 
sedangkan municipal dapat diartikan secara harfiah sebagai citizen yang hidup dalam kota bebas tanpa intervensi. Konsekuensi dari konsep tersebut secara ekologis mampu mendorong masyarakat rasional di suatu wilayah tertentu untuk memberikan argumen secara spesifik tentang haknya sebagai warga negara dan kepentingan ekologinya (Biehl, 1999:173). Kegusaran Bookchin muncul ketika kata libertarian diselewengkan oleh pemerintah dan korporasi demi kepentingan privat yang tak lain adalah penumpukan property. Paham libertariasnism menjadi lebih reduksionis dan bergeser pada propertarianisme sebagai sarana akumulasi privatisasi barang. Langkah yang diambil oleh Bookchin mula-mula adalah mendidik masyarakat sebagai citizen yang mampu memberikan argumen rasional. Sehingga masyarakat/komunitas pada wilayah tertentu mampu berdebat dalam rangka melindugi haknya sebagai warga negara sekaligus kepentingan ekologisnya. Bookchin mencicil perjuangan tersebut demi menahan dominasi dari kepentingan nasional atas eksploitasi pada alam dan warga negaranya. Artinya masyarakat harus mampu lepas dari kepentingan nasional untuk kemudian mengkonservasi wilayahnya "Libertarian municipalism proposes that land and enterprises be placed increasingly in the custody of the community - more precisely, the custody of citizens in free assemblies and their deputies in confederal councils" (Biehl, 1999:184). Perjuangan politis dengan upaya mengaktifkan etika lingkungan ini dianggap berhasil jika perspektif komunitas berikut pikrian ekologisnya dipahami untuk mengahsilkan ecological justice. Perjuangan
Bookchin memang dianggap masih memiliki celah karena eksploitasi bisa saja hadir justru komunitas, karena antroposentrisme bisa saja menyelundup masuk. Masih banyak celah untuk memprovokasi masyrakat untuk bertindak tidak adil pula bagi alam. Namun hal itu harus dianggap sebagai upaya mengaktifkan fungsi citizenship dalam masyarakat sebagai subjek dan bukan objek dihadapan intervensi pemerintah pada mereka dan alam. Jalan yang dimabil Bookchin memberikan tipping point bagi pemikir selanjutnya agar peradaban bisa tumbuh dengan etika ecocentrisme yang mungkin masih terbilang asing agar terus diperdebatkan

Jalan peradaban tersebut dilanjutkan oleh Christopher D Stone, yang kemudian berani untuk mempertanyakan dalam bukunya “Should Trees Have Standing?"(1996) yang menggugat apakah relasi manusia dan alam harus mendapatkan legitimasi hukum positif sehingga memungkinkan bahwa alam, seperti pohon bisa dihitung juga sebagai citizen. Artinya, alam menjadi memiliki hak yang sama seperti manusia di mata hukum. Pemikiran Stone hadir dari pengalaman ketika terjadi kasus Mineral King Valley, taman nasional Sequoia, yang ingin dirubah oleh Walt Disney menjadi sarana ski yang secara otomatis juga mengundang pembanguna restaurant, penginapan dan bisnis lainnya. Tentunya keinginan itu ditentang oleh Sierra Club, sebuah organisasi lingkungan yang cukup tua di Amerika. Kasus tersebut menarik dan akhirnya melibatkan Stone karena ada anggapan Sierra club tidak memiliki standing yaitu $n$ tidak memiliki hak pada Mineral King atau tanggung jawab sehingga Sierra Club seharusnya merasa tidak dirugikan atau 
bahkan terluka pada proyek yang dilakukan oleh Walt Disney. Tentu saja ini menggelikan, karena bagi Stone yang terluka dan dirugikan bukan Sierra Club secara langsung tapi hilangnya Mineral King Valley dan segera kemewahan lekuk alamnya. Peristiwa tersebut membuat Stone mempertanyakan bahwa apakah mungkin bagi Mineral King Valley untuk membela dirinya sendiri, dengan cara harus memiliki legal standing, atau dalam hal ini personhood. Kasus tersebut berlangsung selama satu dekade dan akhirnya Walt Disney telah kehilangan minatnya pada Mineral King Valley ketika William O. Douglas meluluskan Mineral King Valley untuk dihadirkan dalam persidangan yang kepentingannya diwakilkan oleh Sierra Club (Earth Justice, 2018). Bagi Stone tentu saja objek natural tidak bisa maju dihadapan hukum untuk mengatakan haknya, tapi korporasi juga tidak bisa bicara demi dirinya sendiri maka mereka menyewa pengacara "streams and forests cannot have standing because streams and forests cannot speak. Corporations cannot speak, either; nor can states, estates, infants, incompetents, municipalities,or universities. Lawyers speak for them, as they customarily do for the ordinary citizen with legal problems" (Stone, 2010:8). Pada peristiwa Mineral King Valley ada semangat baru bahwa relasi alam dan manusia mampu dijamin oleh hukum yang sama haknya untuk dihitung sebagai citizen. Buah dari perjuangan Stone dan seluruh environmentalists memungkinkan adanya peningkatan etis pada alam sehingga kini ada argumen rasional untuk benar benar mampu berpindah dari antroposentrisme menuju etika baru yaitu ecocentrisme.

\section{PENUTUP}

Tegangan etis muncul ketika kehendak manusia selalu ingin mendahului kehendak alam. Antroposentrisme yang lahir karena supply pikiran modernisme dan utilititarian harus ditahan oleh ecosentrism agar ada percakapan baru antara manusia dan alam. Libertarian memberi upaya itu ketika hak tidak lagi dilihat kelekatannya pada manusia tapi juga alam. Dua basis pikiran yang terus beroposisi itu menjadi landasan argumen mengapa bagi utilitarian, kebakaran hutan di Kalimantan tidak dihitung sebagai kejahatan, dan sebaliknya bagi seorang libertarian sungai di New Zealand harus memiliki legal standing untuk menuntut haknya di mata hukum untuk tetap jernih.

Perdebatan dua jenis etis menjadi penting untuk diucapkan secara akademis agar jernih dalam melihat persoalan alam. Ketajaman argumen telah menghadirkan jalan baru, yang lahir justru dari lokasi yang terkesan teramat eksploitatif pada alam seperti Amerika dengan stigma banyak industry besar tumbuh di negara tersebut. Rachel Carlson yang berupaya mengingatkan bahaya pestisida bagi jejaring ekologis, Bookchin yang ingin melakukan desentralisasi agar masyarakat bisa berupaya menjaga pengalamannya dengan alam tanpa campur tangan pemerintah dan Stone yang berupaya menghadirkan Mineral King Valley, sebuah taman nasional, untuk dihitung sebagai subjek hukum adalah gerakan yang harus dilanjutkan untuk memaksimalkan keseimbangan hubungan manusia dan alam. Kenikmatan untuk hidup berdampingan dengan alam nyatanya tidak hadir dalam satu kali debat tapi juga membutuhkan pergulatan dengan berbagai analisis biologis, politis, 
bahkan hukum positif. Perjuangan itu hanya dimungkinkan jika dialami dan disadari melalui peristiwa yang otentik, sehingga melekat pada angan publik bahwa alam harus dan mampu menulis hukumnya sendiri.

Jalan sepi sederet environmentalists ini ingin memastikan bahwa harus ada relasi baru yang tidak dominatif dan hirarkis pada alam. Tulisan ini tidak hanya ingin menunjukkan posisi etis pada setiap kejahatan alam tapi juga ingin memastikan debat itu tiba di Kalimantan dan model pengalaman suku Maori menjadi juga diperhitungkan yang dapat dipastikan juga ada di sekeliling nusantara. Sehingga, kelak ada sebuah kewajaran bagi sungai sungai untuk tetap mengalir, hak lembah untuk berlekuk, burung untuk berkepak dan pohon untuk tidak terbakar.

\section{DAFTAR PUSTAKA}

Biehl, Janet. 1999. The Murray Bookchin Reader. London, Black Rose Books

Bookchin, Murray,1982. The Ecological Freedom, California: Cheshire books

Carson, Rachel, 1994. The Silent Spring. Fawcett publications, inc., Greenwich, conn.

Garrard, Greg, 2004. Ecocriticism. London Routledge

https://www.nytimes.com/2016/07/14/world/

what-in-the-world/in-new-zealand-landsand-rivers-can-be-people-legallyspeaking.html diakses pada 11/24/2018 https://www.nytimes.com/2016/07/14/world/ what-in-the-world/in-new-zealand-landsand-rivers-can-be-people-legallyspeaking.html diakses pada 11/24/2018 https://www.theguardian.com/world/2017/ma $\mathrm{r} / 16 /$ new-zealand-river-granted-samelegal-rights-as-human-being diakses pada $11 / 24 / 2018$

MacKinnon, Barbara and Fiala. 2015. Ethics:

Theory and Contemporary Issues, California: Cengage Learning

Millennium Ecosystem Assessment (2003)

Ecosystems and Well-being: A Framework for Assessment. Washington DC: Island Press, halaman. 142 diakses pada $11 / 27 / 2018$

Stone, Christopher, 2010. Should Trees Have Standing?, New York: Oxford Univeristy Press 